\title{
Retinoid $X$ receptor activities of source waters in China and their removal efficiencies during drinking water treatment processes
}

\author{
JIANG WeiWei ${ }^{1}$, YAN Ye ${ }^{1}, \mathrm{LI} \mathrm{Na}^{1}$, MA Mei ${ }^{*}$, WANG DongHong ${ }^{1}$, RAO KaiFeng ${ }^{1}$, \\ WANG ZiJian $^{1} \&$ SATYANARAYANAN Senthil Kumaran ${ }^{2}$ \\ ${ }^{1}$ State Key Laboratory of Environmental Aquatic Chemistry, Research Center for Eco-Environmental Sciences, Chinese Academy of Sciences, \\ Beijing 100085, China; \\ ${ }^{2}$ Unit of Toxicology, Bharathiar University, Coimbatore 641046, India
}

Received March 24, 2011; accepted August 18, 2011; published online January 3, 2012

\begin{abstract}
There is increasing evidence of estrogenic activities of source waters and drinking waters in China based on estrogen receptors (ERs) testing. However, relating such activities to retinoid X receptors (RXRs) in both drinking and source waters are lacking. To rectify this situation, we assessed 23 source water samples from six major river systems in China. We also collected samples at various stages of water processing from three drinking water treatment plants (DWTPs) using a two-hybrid RXR yeast assay with and without metabolism. No RXR agonistic activity was observed, but significant antagonistic activity was detected in all sample extracts. The RXR antagonistic activities of source water sample extracts ranged from $15.2 \%$ to $57.8 \%$ without metabolism and $11.5 \%$ to $68.3 \%$ with metabolism, respectively. In the drinking water treatment processes, RXR antagonistic activities without metabolism and with metabolism of up to $31.4 \%$ and $37.5 \%$ were removed, respectively. Nevertheless, the remaining RXR antagonists in treated drinking water from these source waters could still be harmful to human health. To the best of our knowledge, the occurrence of in vitro RXR disruption activities in source and drinking water has not been previously reported in China. Therefore, an attempt was made to conduct detailed studies investigating RXR disrupting activities and their possible risks in source and drinking water.
\end{abstract}

source water, drinking water, retinoid $\mathrm{X}$ receptor, yeast assay, bioassay

Citation: Jiang W W, Yan Y, Li N, et al. Retinoid X receptor activities of source waters in China and their removal efficiencies during drinking water treatment processes. Chin Sci Bull, 2012, 57: 595-600, doi: 10.1007/s11434-011-4906-0

Over the past several decades, a number of different chemicals that are widely distributed in the environment have been found to disrupt delicate endocrine systems in wildlife and humans [1]. These endocrine disrupting chemicals (EDCs) disrupt various biological processes results in developmental degeneration and reduced fecundity, as well as an increase in breast cancer in humans [2]. The principle anthropogenic sources of EDCs include pharmaceutical compounds, wastewater plant effluents, agricultural fertilizers, and fish farming wastes [3-5]. Because EDCs are water-soluble, most conventional water treatment processes that are applied in China (e.g. chlorination, coagulation and

*Corresponding author (email: mamei@rcees.ac.cn) sedimentation) do not completely remove these chemicals [6,7]. EDCs are biologically active at very low concentrations and have been detected in drinking water [8,9]. Accordingly, there has been an increased effort to monitor the occurrence of these chemicals in source waters in China.

To date, most research has focused on estrogenic disruption activity via estrogenic receptors (ERs) in water. It is also important to investigate retinoic acid hormone disruption activity via the retinoid $\mathrm{X}$ receptor (RXR); however, very little research on this aspect has been conducted. Retinoic acid is necessary for vision and plays an essential role in apoptosis and differentiation of embryonic cells that control the growth of epithelial cells in the skin, gastrointestinal tract, and bones [10]. Retinoic acid also affects the nervous 
system and immune system, acts as anti-oxidative agent, and is involved in the biosynthesis of another antioxidant, coenzyme Q [11]. Suppressive effects of retinoic acid in cancer development have also been described [12]. Retinoic acid acts via RXR and EDCs that can also act on RXRs would disturb normal retinoic acid signaling [13]. Human exposure to these chemicals commonly occurs though air and food, but the primary route of exposure is through drinking water $[14,15]$. Thus, it is important to monitor the occurrence of RXR activity in drinking water. There is also a need to further investigate RXR activities in source waters in China and the removal efficiency of these compounds by drinking water treatment plants. The results of such investigations would be important for formulating management policies relating to source water protection and water treatment technology.

The development of efficient methods for evaluating biological activities in water samples will require further development of in vitro bioassays with high sensitivity. The development of rapid response methods using simple equipment has also become an attractive alternative to conventional chemical analytical techniques [16]. Among bioassays that have been considered, the yeast assay was successfully applied to determine activities in chemical and/or environmental samples [17]. Although many EDCs can survive drinking water treatment, little is known about the fate of RXR activity in drinking water [18]. Because there is no metabolic enzyme system in cell lines and metabolism could change the RXR activity of chemicals in water, the results from in vitro tests will not reflect the actual RXR activity of water intake by humans and animals. Therefore, to simulate the exposure conditions in vivo, an S9 mixture was introduced as a metabolic enzyme [19]. The goal of the present study is to screen for RXR activity in source and drinking water using a two-hybrid yeast assay, and to evaluate the removal efficiency of drinking water treatment processes.

\section{Materials and methods}

\subsection{Chemicals and materials}

Dichloromethane, hexane and methanol (HPLC grade) were obtained from J. T. Baker (USA) and 9-cis-RA (9cRA, 98\%) and dimethyl sulfoxides (DMSO, 99.5\%) were obtained from Sigma Chemical (USA). For all chemicals, stock solutions were prepared in DMSO. Oasis hydrophilic lipophilic balance (HLB) cartridges $(500 \mathrm{mg}, 6 \mathrm{~mL}$ ) from Waters Corporation (USA) were used for solid phase extraction (SPE). Glass fiber filters (APFF, pore size $0.45 \mu \mathrm{m}$ ) were purchased from Millipore (USA) and pyrolyzed at $450^{\circ} \mathrm{C}$ for $4 \mathrm{~h}$ prior to use. Purified water used in all experiments was prepared with a Milli-Q water purification system (Millipore, USA).

\subsection{Sample collection}

Samples of 23 source waters, including reservoirs and rivers that supply water to local waterworks, were collected between March 2010 and July 2010. The study area covered six out of seven major river systems of China. All six river systems are of concern because of the local pollution situation. Site information is listed in Table 1.

Samples (of $20 \mathrm{~L}$ ) were also collected from three drinking water treatment plants (DWTP) that processed source waters at sites S5 (North China), S14 (Middle China) and S16 (East China) (Table 2). Samples were collected in pre-cleaned amber glass bottles that had been soaked in $10 \%$ nitric acid overnight, chromic acid solution for $30 \mathrm{~min}$, washed three times in double-distilled water and then dried in a furnace at $450^{\circ} \mathrm{C}$ for at least $4 \mathrm{~h}$. Before sample collection, the bottle was also washed three times with the sampled water. An appropriate amount of methanol $(2 \mathrm{~mL} / \mathrm{L}$ water sample) was added immediately after sampling to suppress possible biotic activities. Samples were stored at $4^{\circ} \mathrm{C}$ and were treated within $48 \mathrm{~h}$.

\subsection{Sample preparation}

The water samples were filtered through pre-baked glass fiber filters to remove insoluble material, and then extracted

Table 1 Information from sampling sites

\begin{tabular}{|c|c|c|c|c|c|}
\hline Site & Type & Site & Type & Site & Type \\
\hline \multicolumn{2}{|c|}{ Songhua River $^{\text {a) }}$} & \multicolumn{2}{|c|}{ Yangtze River } & \multicolumn{2}{|c|}{ Huai River } \\
\hline $\mathrm{S} 1$ & River & S6 & River & S16 & River \\
\hline \multirow[t]{2}{*}{$\mathrm{S} 2$} & Reservoir & S7 & River & S17 & River \\
\hline & & S8 & River & S18 & River \\
\hline \multicolumn{2}{|c|}{ Liao River } & S9 & River & S19 & River \\
\hline $\mathrm{S} 3$ & Reservoir & S10 & River & & \\
\hline \multirow[t]{2}{*}{$\mathrm{S} 4$} & Reservoir & S11 & River & \multicolumn{2}{|c|}{ Pearl River } \\
\hline & & $\mathrm{S} 12$ & Lake & $\mathrm{S} 20$ & Reservoir \\
\hline \multicolumn{2}{|c|}{ Hai River } & S13 & Reservoir & $\mathrm{S} 21$ & Reservoir \\
\hline \multirow[t]{2}{*}{ S5 } & Reservoir & S14 & River & $\mathrm{S} 22$ & Reservoir \\
\hline & & S15 & Reservoir & $\mathrm{S} 23$ & River \\
\hline
\end{tabular}

a) River system.

Table 2 Flow scheme of drinking water treatment plants

\begin{tabular}{|c|c|c|}
\hline DWTP1 & DWTP2 & DWTP3 \\
\hline Source water S5 $\left(\mathrm{A} 1^{\mathrm{a})}\right)$ & Source water S14 (A2) & Source water S16 (A3) \\
\hline Pre-chlorination (B1) & Pre-chlorination (B2) & Coagulation (B3) \\
\hline Coagulation (C1) & Coagulation & $\begin{array}{l}\text { Coal and sand filtration } \\
\text { (C3) }\end{array}$ \\
\hline $\begin{array}{l}\text { Coal and sand filtration } \\
\text { (D1) }\end{array}$ & Rapid filtration (C2) & $\begin{array}{l}\text { Secondary filtration } \\
\text { (D3) }\end{array}$ \\
\hline $\begin{array}{l}\text { Active Carbon filtration } \\
\text { (E1) } \\
\text { Secondary chlorination } \\
\text { (F1) }\end{array}$ & $\begin{array}{l}\text { Secondary chlorina- } \\
\text { tion (D2) }\end{array}$ & \\
\hline
\end{tabular}


according to methods used in our previous study [20]. The water samples were extracted using HLB cartridges that had been pre-conditioned with $5 \mathrm{~mL}$ dichloromethane, $5 \mathrm{~mL}$ methanol, and $5 \mathrm{~mL}$ water. During extraction, the cartridges were forced under vacuum at a flow rate of approximately $6 \mathrm{~mL} / \mathrm{min}$, and then kept under vacuum for $5 \mathrm{~min}$ to dry the water. The cartridges were then eluted three times with $15 \mathrm{~mL}$ dichloromethane. The elutions were combined and filtered through anhydrous sodiumsulfate $\left(\mathrm{Na}_{2} \mathrm{SO}_{4}\right)$ to remove residual water, after which they were evaporated to $2 \mathrm{~mL}$ in a rotary evaporator (R-200, Buchi, Switzerland) at $40^{\circ} \mathrm{C}$. The $2 \mathrm{~mL}$ extract was subsequently dried under a nitrogen stream, after which it was immediately reconstituted to $0.2 \mathrm{~mL}$ with DMSO. A blank sample only consisting of purified water was also run alongside the samples as a control. Throughout the experiment, all laboratory materials were stored in glass or polytetrafluoroethene (PTFE) to prevent contamination.

\subsection{Yeast assay}

The yeast assay was conducted as described previously by our research group [21,22], with some modifications. The yeast strain used in the present study was Y187 MAT $_{\alpha}$, ura3-52, his3-200, ade2-101, trp1-901, leu2-3, 112, gal4 $\Delta$,

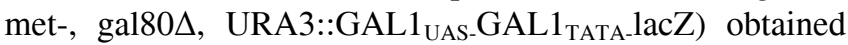
from Clontech (Palo Alto, CA, USA). Yeast cells were cotransformed with pGBT9 $\mathrm{hRXR}_{\beta}$ and pGAD424 GRIP1/FL using the lithium acetate method and then selected by growth on synthetic dextrose (SD) agar (lacking leucine and tryptophan) according to Clontech yeast protocols handbook. Clones growing on the SD/-Leu/-Trp plate were selected for culture in liquid SD/-Leu/-Trp medium. In this assay, yeast is grown at an exponential rate overnight at $30^{\circ} \mathrm{C}$, then centrifuged at $130 \mathrm{r} / \mathrm{min}$ and diluted to an optical density of 0.75 at $600 \mathrm{~nm}\left(\mathrm{OD}_{600}\right)$ with synthetic dextrose/-Leu/-Trp medium (SD medium). All samples were assayed at least in triplicate. Each assay group included a positive 9cRA control and a negative DMSO control. A procedural blank that was subjected to SPE to monitor for any false positive results was run alongside the samples. Each sample was diluted in a $1: 2$ series to give a total of four concentrations diluted in DMSO. The $5 \mu \mathrm{L}$ serial dilutions of the tested samples were combined with $995 \mu \mathrm{L}$ of medium that contained approximately $5 \times 10^{3}$ yeast cells $/ \mathrm{mL}$, resulting in a test culture in which the volume of DMSO did not exceed $0.5 \%$ of the total volume. In the case of the metabolic test, the S9 mixture was added. S9 was prepared from the livers of male Sprague-Dawley rats that were pre-treated with 3-methyl- cholanthrene and 3-phenobarbital according to the method described by Ames et al. [19]. Water and cofactor $\left(\mathrm{MgCl}_{2} \cdot 6 \mathrm{H}_{2} \mathrm{O}, \mathrm{KCl}, \mathrm{G}-6-\mathrm{P}\right.$, nicotinamide adenine dinucleotide phosphate, nicotinamide adenine dinucleotide, $\mathrm{Na}_{2} \mathrm{HPO}_{4}$ and $\mathrm{NaH}_{2} \mathrm{PO}_{4}$ ) were added to the SD/-Leu/-Trp medium according to the method described Takatori et al.
[23]. Next, $200 \mu \mathrm{L}$ of the test cultures were transferred into each well of a 96-well plate. The samples were then incubated at $30^{\circ} \mathrm{C}$ with vigorous orbital shaking $(800 \mathrm{r} / \mathrm{min})$ on a titer plate shaker for $2 \mathrm{~h}$, after which the $\mathrm{OD}_{600}$ value was measured. The volume of extract in each well represented $100 \mathrm{~mL}$ of raw water.

Test cultures of $150 \mu \mathrm{L}$ were collected and $120 \mu \mathrm{L}$ of test buffer and $20 \mu \mathrm{L}$ of chloroform were added to each culture. The cultures were mixed carefully (vortex $25 \mathrm{~s}$ ) and pre-incubated for $10 \mathrm{~min}$ at $30^{\circ} \mathrm{C}$ and $1300 \mathrm{r} / \mathrm{min}$. The enzyme reaction was then triggered by adding $40 \mu \mathrm{L}$ $O$-nitrophenyl- $\beta$-D-galactopyranoside (ONPG) and 4 $\mathrm{mg} / \mathrm{mL}$ test buffer and incubating the sample at $30^{\circ} \mathrm{C}$ and $800 \mathrm{r} / \mathrm{min}$. Next, $100 \mu \mathrm{L}$ of $1 \mathrm{~mol} / \mathrm{L}$ sodium carbonate $\left(\mathrm{Na}_{2} \mathrm{CO}_{3}\right)$ was added to terminate the reactions within 60 min, after which $200 \mu \mathrm{L}$ of the supernatant was transferred into a new 96-well plate and the optical density $\left(\mathrm{OD}_{420}\right)$ was measured at $420 \mathrm{~nm}$. To ensure that the activity in the bioassay was caused by true antagonistic responses and not by cytotoxicity, cell viability was also measured and determined by spectrophotometric analysis after exposure as the change in cell density $\left(\mathrm{OD}_{600}\right)$ in the assay medium.

\subsection{Data analysis}

$\beta$-galactosidase activity was calculated according to the following equation

$$
U=\left(\mathrm{OD}_{420 \mathrm{~s}}-\mathrm{OD}_{420 \mathrm{~b}}\right) /\left(t \times V \times \mathrm{OD}_{600}\right),
$$

where $U$ is the $\beta$-galactosidase activity of the sample; $\mathrm{OD}_{420 \mathrm{~s}}$ and $\mathrm{OD}_{420 \mathrm{~b}}$ are the optical density of the enzyme reaction supernatant of the sample and blank, respectively; $\mathrm{OD}_{600}$ is the optical density of the sample at $600 \mathrm{~nm}$; $t$ is the incubation duration of the enzyme reaction; $V$ is the volume of the test culture.

The antagonistic activity of sample was calculated according to the following equation:

$$
\text { Antagonistic activity }=\left(1-U_{\mathrm{s}} / U_{\mathrm{p}}\right) \times 100 \%,
$$

where $U_{\mathrm{p}}$ and $U_{\mathrm{s}}$ represent the $\beta$-galactosidase activity of the positive control $(1.5 \mathrm{mg} / \mathrm{L} 9 \mathrm{cRA})$, and in the presence of $1.5 \mathrm{mg} / \mathrm{L}$ of $9 \mathrm{cRA}$, respectively.

\section{Results and discussion}

\subsection{Response to source water extracts}

No RXR agonistic activity was observed in any of the source water sample extracts (data not shown); however, RXR antagonistic activity was found in all extracts. The observed activity ranged from $15.2 \%$ to $57.8 \%$ and $11.5 \%$ to $68.3 \%$ without and with metabolism, respectively. The presence of RXR antagonistic activity of source waters varied spatially (Figure 1), and RXR antagonists were found to exist in many source waters in China. 


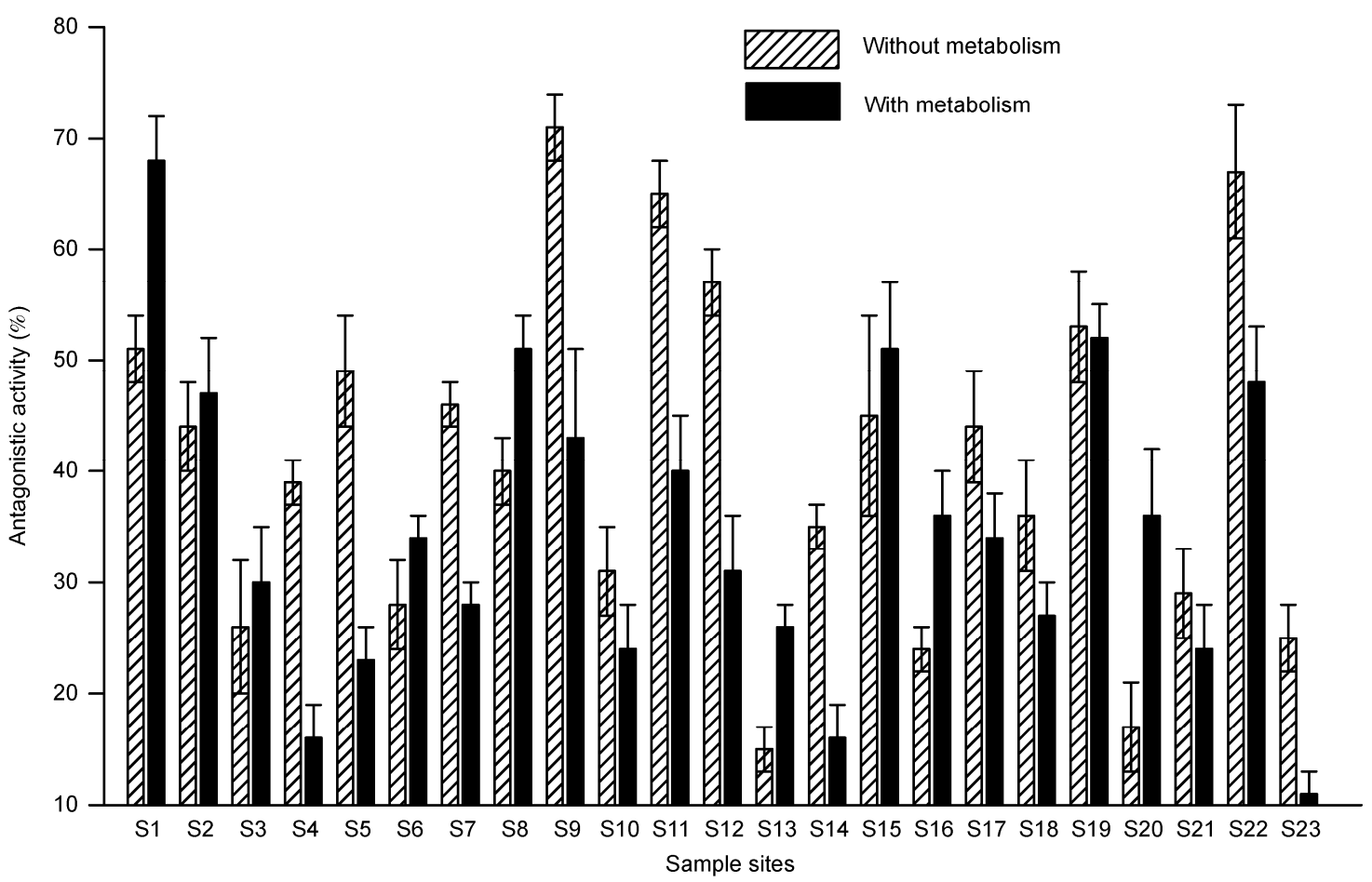

Figure 1 RXR antagonistic activities of source sample extracts $(100 \mathrm{~mL}$ raw water/well). Values are presented as the mean \pm S.D. $(n=3)$.

Various types of environmental contamination by chemical compounds such as anti-oxidants, organochlorines, organophosphates, antimicrobials, estrogens and progestogens, and various types of industrial contamination such as pesticides, pharmaceuticals and personal care products (PPCPs) have been found in source and drinking waters [24-28]. Some of these contaminants have been identified as RXR agonists or antagonists [22] and include Bisphenol A (BPA), multiple phenols, phthalic acid esters (PAEs) and organic chlorine pesticides (OCPs) that have been found in various aquatic systems in China [29-32]. In the present study, most of the sample sites with relatively high RXR antagonistic activities were located in national grain production areas in China. The massive use of OCPs in these areas would contribute considerably to total activity levels [33]. However, the lack of sufficient data pertaining to toxic RXR antagonists has prevented the identification of these chemicals in source waters.

The RXR activities in nine out of 23 extracts increased after metabolism, while the activities in the remaining 14 samples decreased. The results also indicate that the composition profile of contamination in the samples is expected to be complicated. Some in vivo experiments have shown that metabolic enzymes can increase or decrease the estrogenic activity of chemicals such as BPA and 4-NP, but that these involve many biochemical processes such as hydroxylation, methylation, sulfonation, glucuronidation, and arylation [34-36]. The results from the present study have demonstrated that RXR antagonists can also be activated or deactivated after metabolism.
The results indicate that the source waters in China are generally affected by RXR antagonists. Therefore, an evaluation of the removal of these contaminants by DWTP is of considerable environmental importance.

\subsection{Response to drinking water extracts}

As was the case for source waters, no RXR agonistic activity was observed in any of the samples, but significant antagonistic activity was induced in all sample extracts (Figure 2). The removal efficiencies of RXR antagonistic activities of DWTP1, DWTP2 and DWTP3 were $15.2 \%$, $31.4 \%$ and $29.2 \%$ without metabolism, and $10.0 \%$, $37.5 \%$ and $30.2 \%$ with metabolism, respectively. The conventional drinking water treatments were ineffective with regard to the removal of RXR antagonists.

The removal efficiencies of RXR antagonists by the processes of the DWTPs were generally different in samples with or without metabolism. For example, at DWTP1 and DWTP2 chlorination slightly increased the RXR antagonistic activities without metabolism, while such activities decreased with metabolism, indicating that the metabolites of RXR antagonists were less active in chlorinated samples. Nevertheless, the RXR antagonistic activity decreased after chlorination at DWTP3. Previous studies have indicated that chlorination does not effectively remove EDCs; indeed, in some cases the levels of EDCs increased with chlorination [37,38]. The same trends were found in association with other processes. When compared with other processes, coagulation seemed a more effective method for removing 

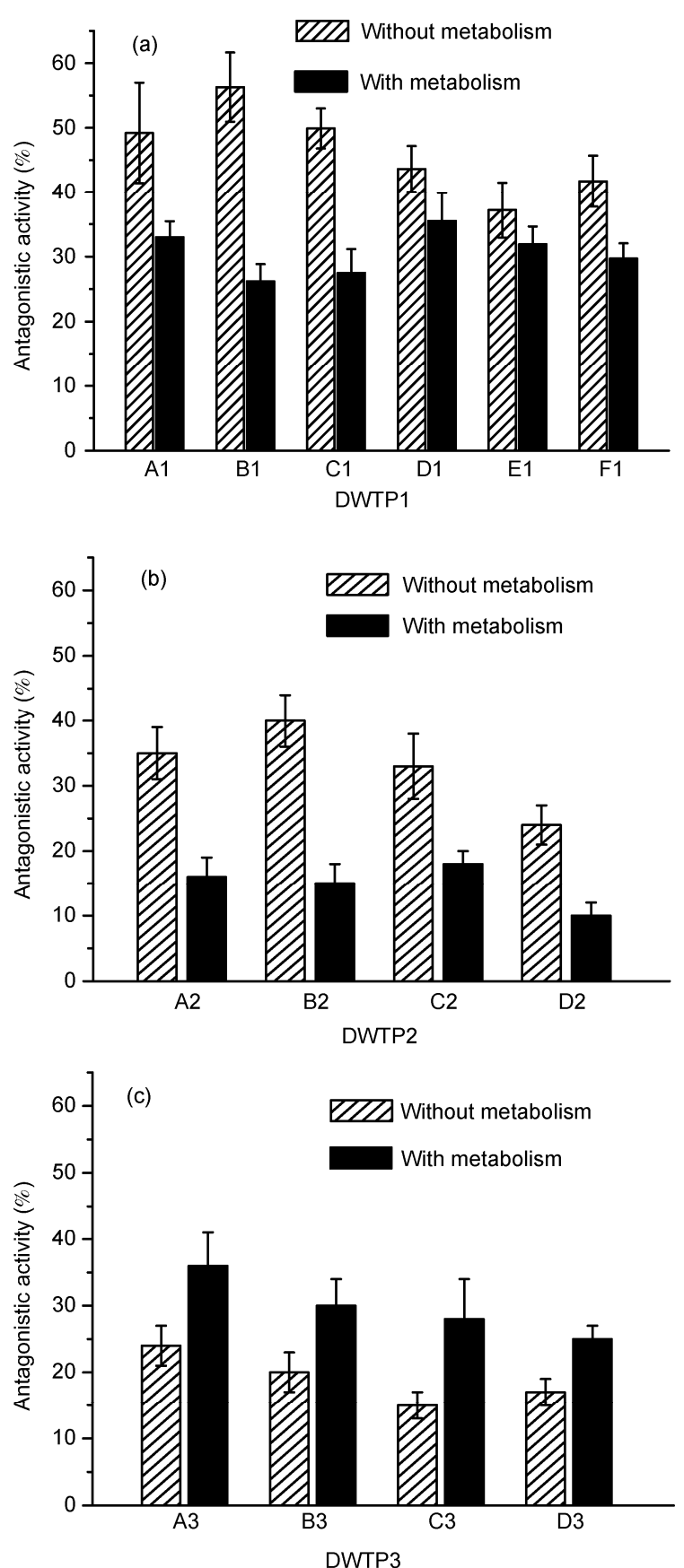

Figure 2 RXR antagonistic activities of extracts of samples from various drinking water treatment plants $(100 \mathrm{~mL}$ raw water/well $)$. Values are presented as the mean \pm S.D. $(n=3)$.

RXR antagonists, although its efficiency did not exceed $25 \%$. According to another study, coagulation removed less than $25 \%$ of the EDCs or PPCPs [18]. Ormad et al. [39] demonstrated that adsorption onto coal, sand or activated carbon was a very efficient technique for removing about $60 \%$ of the OCPs from the water. However, since filtration is not a destructive process, the contamination passes from one medium to another, resulting in the sorbent becoming a new source of pollution. In summary, the removal efficiencies of RXR antagonistic activity were variable, even differing between the same processes at different DWTPs. These findings indicate that the removal efficiency of RXR antagonists is expected to be largely dependent on the composition of solutes in water.

Although the concentrations of EDCs were very low in source and drinking waters, there is still increasing concern regarding the lack of understanding of the fate of RXR antagonists during drinking water treatment considering that even trace amounts of natural hormones can disturb the endocrine system [24]. Since conventional drinking water treatment processes (chlorination, coagulation and sand filtration) are often inefficient for low-concentration contaminants, finished waters can be expected to contain significant amounts of EDCs that could jeopardize drinking water quality and cause risks to human health [40]. In the present study, DWTPs were found to remove maximum levels of only $31.4 \%$ without metabolism and $37.5 \%$ with metabolism of RXR antagonistic activity. These results indicate that DWTP could not completely remove the RXR antagonist, as was also the case for other EDCs. Since RXR plays an important role in the mediation of hormones in human health and is a component of disrupting substances that is still harmful to wild animals and humans in source water, it is possible that the finished drinking water might be harmful to human health.

\section{Conclusions}

RXR antagonistic activities were found in all extracts of samples from 23 source waters in China and drinking water treatment processes of three DWTPs supplied by three out of the 23 source waters. None of the samples induced agonistic activity. The source waters were generally affected by RXR antagonists. Conventional drinking water treatment processes could not completely remove these RXR antagonists, implying current risks to human health. The RXR two-hybrid yeast assay can be applied as an important and useful method for evaluation of drinking water safety, particularly as it facilitates the efficient detection of RXR disruptors. Further studies are needed to identify the compounds responsible for RXR antagonistic activity to provide useful information for environmental risk assessments and water treatment technology.

This work was supported by the Environmental Protection National Commonweal Research Project (200909040) and International Scientific and Technological Cooperation Projects by the Ministry of Science and Technology of China (2009DFA91920).

1 Colborn T, Saal F S V, Soto A M. Developmental effects of endocrine-disrupting chemicals in wildlife and humans. Environ Health Perspect, 1993, 101: 378-384

2 Crews D, Willingham E, Skipper J K. Endocrine disruptors: Present issues, future directions. Q Rev Biol, 2000, 75: 243-260

3 Tashiro Y, Takemura A, Fujii H, et al. Livestock wastes as a source 
of estrogens and their effects on wildlife of Manko tidal flat, Okinawa. Mar Pollut Bull, 2003, 47: 143-147

4 Yamazaki F. Sex control and manipulation in fish. Aquaculture, 1983, 33: 329-354

5 Desbrow C, Routledge E J, Brighty G C, et al. Identification of estrogenic chemicals in STW effluent. 1. Chemical fractionation and in vitro biological screening. Environ Sci Technol, 1998, 32: 15491558

6 Li N, Wang D H, Zhou Y Q, et al. Dibutyl phthalate contributes to the thyroid receptor antagonistic activity in drinking water processes. Environ Sci Technol, 2010, 44: 6863-6868

7 Yuan S G, Wang D H, Ma M, et al. Assessment on removal effect of different advanced treatment techniques in waterworks. Chinese J Environ Eng, 2008, 2: 586-590

8 Magi E, Scapolla C, Di Carro M, et al. Determination of endocrinedisrupting compounds in drinking waters by fast liquid chromatography-tandemmass spectrometry. J Mass Spectrom, 2010, 45: 10031011

9 Kuch H M, Ballschmiter K. Determination of endocrine-disrupting phenolic compounds and estrogens in surface and drinking water by HRGC-(NCI)-MS in the picogram per liter range. Environ Sci Technol, 2001, 35: 3201-3206

10 Janosek J, Hilscherova K, Blaha L, et al. Environmental xenobiotics and nuclear receptors-Interactions, effects and in vitro assessment. Toxicol Vitro, 2006, 20: 18-37

11 Bentinger $M$, Turunen $M$, Zhang X X, et al. Involvement of retinoid $\mathrm{X}$ receptor alpha in coenzyme Q metabolism. J Mol Biol, 2003, 326: 795-803

12 Sun S Y, Lotan R. Retinoids and their receptors in cancer development and chemoprevention. Crit Rev Oncol Hemat, 2002, 41: 41-55

13 Van der Plas S A, Lutkeschipholt I, Spenkelink B, et al. Effects of subchronic exposure to complex mixtures of dioxin-like and nondioxin-like polyhalogenated aromatic compounds on thyroid hormone and vitamin A levels in female Sprague-Dawley rats. Toxicol Sci, 2001, 59: 92-100

14 Fürst P. Dioxins, polychlorinated biphenyls and other organohalogen compounds in human milk. Levels, correlations, trends and exposure through breastfeeding. Mol Nutr Food Res, 2006, 50: 922-933

15 Weschler C. Changes in indoor pollutants since the 1950s. Atmos Environ, 2009, 43: 153-169

16 Campbell C, Borglin S, Green F, et al. Biologically directed environmental monitoring, fate, and transport of estrogenic endocrine disrupting compounds in water: A review. Chemosphere, 2006, 65: $1265-1280$

17 Vermeirssen E L M, Burki R, Joris C, et al. Characterization of the estrogenicity of swiss midland rivers using a recombinant yeast bioassay and plasma vitellogenin concentrations in feral male brown trout. Environ Toxicol Chem, 2005, 24: 2226-2233

18 Westerhoff P, Yoon Y, Snyder S, et al. Fate of endocrine-disruptor, pharmaceutical, and personal care product chemicals during simulated drinking water treatment processes. Environ Sci Technol, 2005, 39: 6649-6663

19 Ames B N, Lee F D, Durston W E. Improved bacterial test system for detection and classification of mutagens and carcinogens. Proc Natl Acad Sci USA, 1973, 70: 782-786

20 Ma M, Rao K F, Wang Z J. Occurrence of estrogenic effects in sewage and industrial wastewaters in Beijing, China. Environ Pollut, 2007, 147: 331-336

21 Ma M, Li J, Wang Z J. Assessing the detoxication efficiencies of wastewater treatment processes using a battery of bioassays/biomarkers. Arch Environ Contam Toxicol, 2005, 49: 480-487
22 Li J, Ma M, Wang Z J. A two-hybrid yeast assay to quantify the effects of xenobiotics on retinoid $\mathrm{X}$ receptor-mediated gene expression. Toxicol Lett, 2008, 176: 198-206

23 Takatori S, Kitagawa Y, Oda H, et al. Estrogenicity of metabolites of benzophenone derivatives examined by a yeast two-hybrid assay. $\mathbf{J}$ Health Sci, 2003, 49: 91-98

24 Benotti M J, Trenholm R A, Vanderford B J, et al. Pharmaceuticals and endocrine disrupting compounds in US drinking water. Environ Sci Technol, 2009, 43: 597-603

25 Casajuana N, Lacorte S. Presence and release of phthalic esters and other endocrine disrupting compounds in drinking water. Chromatographia, 2003, 57: 649-655

26 Kuster M, Lopezdealda M, Hernando M, et al. Analysis and occurrence of pharmaceuticals, estrogens, progestogens and polar pesticides in sewage treatment plant effluents, river water and drinking water in the Llobregat river basin (Barcelona, Spain). J Hydrol, 2008, 358: $112-123$

27 Lin Y, Shi Y, Jiang M, et al. Removal of phenolic estrogen pollutants from different sources of water using molecularly imprinted polymeric microspheres. Environ Pollut, 2008, 153: 483-491

28 Murray K E, Thomas S M, Bodour A A. Prioritizing research for trace pollutants and emerging contaminants in the freshwater environment. Environ Pollut, 2010, 158: 3462-3471

29 Wu B, Zhang X X, Zhang X L, et al. Semi-volatile organic compounds and trace elements in the Yangtze River source of drinking water. Ecotoxicology, 2009, 18: 707-714

30 Zhang Z L, Hong H S, Zhou J L, et al. Fate and assessment of persistent organic pollutants in water and sediment from Minjiang River Estuary, Southeast China. Chemosphere, 2003, 52: 1423-1430

31 Zhong W J, Wang D H, Xu X W, et al. Screening level ecological risk assessment for phenols in surface water of the Taihu Lake. Chemosphere, 2010, 80: 998-1005

32 Lemaire G, Balaguer P, Michel S, et al. Activation of retinoic acid receptor-dependent transcription by organochlorine pesticides. Toxicol Appl Pharmacol, 2005, 202: 38-49

33 Li X M, Gan Y P, Yang X P, et al. Human health risk of organochlorine pesticides (OCPs) and polychlorinated biphenyls (PCBs) in edible fish from Huairou Reservoir and Gaobeidian Lake in Beijing, China. Food Chem, 2008, 109: 348-354

34 Legler J, Dennekamp M, Vethaak A D, et al. Detection of estrogenic activity in sediment-associated compounds using in vitro reporter gene assays. Sci Total Environ, 2002, 293: 69-83

35 Pottenger L H, Domoradzki J Y, Markham D A, et al. The relative bioavailability and metabolism of bisphenol $\mathrm{A}$ in rats is dependent upon the route of administration. Toxicol Sci, 2000, 54: 3-18

36 Moffat G J, Burns A, Van Miller J, et al. Glucuronidation of nonylphenol and octylphenol eliminates their ability to activate transcription via the estrogen receptor. Regul Toxicol Pharmacol, 2001, 34: $182-187$

37 Itoh S, Ueda $\mathrm{H}$, Naasaka $\mathrm{T}$, et al. Evaluating variation of estrogenic effect by drinking water chlorination with the MVLN assay. Water Sci Technol, 2000, 42: 61-69

38 Chen C, Wen T, Wang G, et al. Determining estrogenic steroids in Taipei waters and removal in drinking water treatment using highflow solid-phase extraction and liquid chromatography/tandem mass spectrometry. Sci Total Environ, 2007, 378: 352-365

39 Ormad M, Miguel N, Claver A, et al. Pesticides removal in the process of drinking water production. Chemosphere, 2008, 71: 97-106

40 Kim S D, Cho J, Kim I S, et al. Occurrence and removal of pharmaceuticals and endocrine disruptors in South Korean surface, drinking, and waste waters. Water Res, 2007, 41: 1013-1021

Open Access This article is distributed under the terms of the Creative Commons Attribution License which permits any use, distribution, and reproduction in any medium, provided the original author(s) and source are credited. 